\title{
Utopismo e Antiutopismo, em Bloch e Jonas
}

\section{Utopianism and Anti-Utopianism, in Bloch and Jonas}

ANTONIO VALVERDE

\section{Resumo}

Aos quarenta anos de O Princípio Responsabilidade, de Hans Jonas, o ensaio ${ }^{1}$ procede à sondagem exploratória e à análise da tensão ético-política acerca das concepções de utopia e de antiutopia, dispostas e posicionadas pelas filosofias blochiana e jonasiana. Se para Bloch o que tem movido - e, por certo, seguirá movendo - a humanidade recebe sua identidade da docta spes (a esperança compreendida), sob a forma utopia concreta, fundada na ontologia do "ainda-não consciente"; para Jonas, ao contrário, é necessário suplantar a mentalidade utópica, sobremaneira a tecnológica, derivada e executora do projeto baconiano, de modo a facilitar a consolidação da ética da responsabilidade destinada à civilização tecnológica. Se uma posição ético-política finda por interrogar a outra, intenciona-se a explicitação crítica de ambas argumentações, que poderá fornecer alguns elementos de compreensão do problema. A hipótese subjacente aponta para a parte mais vulnerável de O Princípio Responsabilidade, os capítulos V e VI, em que ocorrem a crítica jonasiana à utopia de pressupostos derivados da filosofia marxista, sintetizados e atualizados em O Princípio Esperança, de Ernst Bloch.

Palavras-chave: Ernst Bloch. Hans Jonas. Utopia concreta. Antiutopismo. Princípio esperança. Princípio responsabilidade.

\section{Abstract \\ At forty years of Hans Jonas' The Principle of Responsibility, the essay proceeds with an exploratory survey and an analysis of the ethical-political tension regarding the concepts of utopia and anti-utopia, arranged and positioned by the Blochian and Jonasian philosophies. If for Bloch what has moved - and certainly will continue to move - humanity

\footnotetext{
${ }^{1}$ Ensaio lido durante o VI Colóquio Hans Jonas, realizado no campus Prado Velho da PUCPR, dia 25 de setembro de 2019.

a Pontifícia Universidade Católica de São Paulo (PUC-SP), Brasil. Doutor em Educação (UNICAMP), e-mail: valverde@pucsp.br
} 
receives its identity from the docta spes (the understood hope), in the form of concrete utopia, founded on the ontology of the 'not yet conscious'; for Jonas, on the contrary, it is necessary to overcome the utopian mentality, especially the technological one, derived from and executing the Baconian project, in order to facilitate the consolidation of the ethics of responsibility for technological civilization. If one ethical-political position ends up questioning the other, the critical explanation of both arguments is intended, which may provide some elements of understanding of the problem. The underlying hypotesis points to the most vulnerable part of The Responsibility Principle, chapters V and VI, in which the Jonasian critique of the utopia of assumptions derived from Marxist philosophy occurs, synthesized and updated in Ernst Bloch's The Principle of Hope.

Keywords: Ernst Bloch. Hans Jonas. Concrete utopia. Anti-utopianism. Hope principle. Principle of responsibility.

\begin{abstract}
"A crítica da utopia, que agora concluímos, teria sido demasiado extensa, caso a utopia marxista, em sua estreita aliança com a técnica, não representasse uma versão escatologicamente radicalizada daquilo, para onde 0 ímpeto tecnológico mundial está nos empurrando, sob o signo do progresso, ainda que de forma nada escatológica." (Hans Jonas, 2006, p. 349) ${ }^{2}$
\end{abstract}

"O que caracteriza o poder e a verdade do marxismo é justamente o fato de ele ter dissipado a nuvem que envolvia os sonhos para a frente sem ter apagado as colunas de fogo que neles ardiam, dando-lhes, ao contrário, força e concretude."

(Ernst Bloch, I, 15, 2005, p. 145)

\title{
Deambulação
}

Acaso, há um substrato pessimista na filosofia de Hans Jonas? Por derivação indireta da linhagem de Schopenhauer, Kierkegäard, Nietzsche, Freud e direta de

\footnotetext{
2 "Die hiermit abgeschlossene Kritik de Utopie wäre übertrieben ausführlich gewesen, wenn niche der marxistische Utopismus in seinem engen Bund mit der Technik eine 'eschatologisch' radikalisierte Version dessen darstellte, wohin ganz der uneschatologisch der weltweite technologische Impetus (JONAS, 2003, p. 388)."

3 "[Es bezeichnet gerade die Macht und Wahrheit des Marxismus, daß er die Wolke in den Träumen nach vorwärts vertrieben, aber die Feuersäule in ihnen nicht ausgelöscht, sondern durch Konkret- heit verstärkt hat.] (BLOCH, 1977, p. 165-166)". Segundo Hudson Mandotti de Oliveira trata-se de "uma linda passagem que faz alusão ao êxodo judaico, no deserto inóspito, em que um povo sem Heimat (Pátria), é conduzido pela metáfora da nuvem, que os sustenta com o maná (ן̣ man). No sentido blochiano, são os sonhos diurnos que impulsionam os homens e as colunas de fogo, que mantêm os homens aquecidos durante os períodos curtos de estadia no deserto. Para Bloch, a tocha que arde é o espírito da revolução que os mantém vivos para as possíveis concreções".
} 
Heidegger? Hans Jonas deixa tresandar certo espírito do pessimismo em seu pensamento? Contrariamente, Marx e Bloch não se expendem como pessimistas. Ao final do ensaio em tela, volta-se à questão.

Como nem tudo que reluz é ouro... Hans Jonas, autodeclarado antiutopista radical, em relação à utopia tecnológica e a de matriz baconiana, por firmar posição, deixa à mostra a vulnerabilidade argumentativa da parte final de O Princípio Responsabilidade. Tal se dá de par com as interpretações equivocadas do marxismo, confundido e identificado com o regime comunista, atuante e descontinuado durante o século passado, e em tentativas pouco aprofundadas de elucidação da utopia concreta de Ernst Bloch. Para tanto, de saída, Jonas afirma que "A dinâmica do progresso tecnológico em escada mundial oculta um utopismo implícito, senão quanto ao programa, pelo menos quanto à inclinação". Ao que prossegue, "Isso obriga a uma crítica pormenorizada do ideal utópico. Como tem a seu favor os sonhos mais antigos da humanidade, e agora parece também possuir na técnica os meios para transformar o sonho em empreendimentos, o utopismo, outrora inócuo, tornou-se a mais perigosa das tentações — precisamente porque idealista — da humanidade em nossos dias (JONAS, 2006, p. 22-23)". Ora, se retirada a utopia do cenário político, como fator de negação e de esperança de superação da ordem social excludente, o que restará à humanidade? Conformismo e mais alienação? O abandono da utopia traz o eclipse dos sonhos e implanta a vitória do medo, como parece ocorrer ao tempo presente.

Contudo, as pesquisas relativas à polaridade entre utopismo e antiutopismo, balizadas desde o princípio esperança, por Ernst Bloch, e o de responsabilidade, por Hans Jonas, são pouco numerosas, e, em geral, reproduzem as assertivas jonasianas, sem atentar para as contradições contidas, tampouco aprofundá-las criticamente ${ }^{4}$. As pesquisas publicadas vieram à luz juntamente com análises da ética da responsabilidade, sem considerar de modo adequado o dar a ver dos pressupostos marxistas à elaboração teórica do conceito de utopia concreta, moldados sob a síntese docta spes, a esperança compreendida, ${ }^{5}$ concebidas por Ernst Bloch, em vista do

\footnotetext{
4 A propósito, conferir NOVAES, A. (Org.), O novo espírito utópico, São Paulo, Sesc, 2016.

${ }^{5}$ A propósito da "docta spes", ver "Prefácio". In: BLOCH, Livro I, 2005, p. 17. 
fracasso das utopias tradicionais ${ }^{6}$. Anteriormente, ${ }^{7}$ apontei para o problema em pauta, explicitando as contradições e a ambiguidade da compreensão jonasiana do problema. Aqui, pretendo analisá-lo com consistência, contudo, sem ultrapassar o limite da sondagem exploratória.

\section{Utopismo e antiutopismo}

Se de um lado Jonas deve ser elogiado e reconhecido pela inovação ética acerca da responsabilidade para a civilização tecnológica, contudo, não deve ser endossado em relação à sua crítica ao espírito da utopia. Pois, qual um profeta desarmado, como a parte esquecida das minorias abraâmicas a clamar no deserto, - tanto no da desertificação das megalópoles cobertas de asfalto betuminoso, como no das florestas incendiadas, criminosamente - a chave de compreensão de seu antiutopismo reside nas considerações acerca da troca da orientação vertical das éticas anteriores, modelarmente, desde Platão, pela orientação horizontalizada moderna. Para tanto, Jonas discute o lugar do

Eros platônico, (que esteve) voltado para a eternidade e não (para a) temporalidade, (pois) não era responsável pelo seu objeto. (Em verdade) O que se buscava nele era um 'algo' superior, que não 'seria', mas 'era'. Esse algo, que o tempo não pode afetar e a que nada pode suceder, não pode ser objeto da responsabilidade. [...] (Porque) Só se é responsável por aquilo que é mutável, ameaçado pela deterioração e pela decadência, em suma pelo que há de mortal em sua mortalidade. [...] (Assim) A perspectiva platônica era clara: ela não desejava que o eterno se tornasse temporal, mas sim que, por meio do Eros, o tempo pudesse se tornar eterno 'na medida do possível' (JONAS, 2006, p. 212).

Destarte, a tarefa de amar o que é mortal quedou com os modernos.

Sob esta chave, Jonas esclarece que, desde Kant, Hegel e Marx, o processo histórico assumiu-se como escatológico, pela completa “inversão da perspectiva antiga ("platônica', no sentido amplo de uma tipologia milenar)." A imagem ilustrativa

\footnotetext{
${ }^{6}$ Salvo a tese de Francisco Viana, que ao analisar as críticas a Bloch, não considera relevante a de Jonas. Conferir VIANA, F. A. M., A utopia concreta e o ainda não-consciente, na obra de Ernst Bloch, tese doutoral em Filosofia, PUC-SP, 2015, pp. 237-240.

${ }^{7}$ Apud VALVERDE, A., "A docta spes de Ernst Bloch e o antiutopismo de Hans Jonas", In COSTA, A. F. V. da; CARVALHO, A. B. A. de; VIESENTEINER, J. L.; RIBEIRO, N.; ARAÚJO, P. A. de e SENA, S. (Org.), Heidegger, Jonas e Levinas, São Paulo, ANPOF, 2019. p. 43-58.
} 
utilizada por Jonas troca a posição de verticalidade na ordenação atemporal para a de horizontalidade temporal, com "as ordenadas tornando-se abscissas", a metaforizar o sistema de coordenadas cartesianas. Assim, a "ideia reguladora", de Kant, corresponde a "ideia de bem", de Platão. E "o fim almejado, por exemplo, o 'bem supremo', situa-se na escala temporal, que se estende interminavelmente no futuro do sujeito (JONAS, 2006, p. 213)". Segundo Jonas, o movimento prossegue com Hegel, que foi o

primeiro a dar o passo para uma 'imanentização' radical, [...], pois que, a 'astúcia' da razão age não do exterior, mas na própria dinâmica da história, com intenções bastante distintas dos sujeitos que a executam: (portanto) o objetivo moral é superado pelo poder autônomo dessa dinâmica (JONAS, 2006, p. 214).

Ainda segundo Jonas, com Marx “vem [...] a famosa inversão da dialética hegeliana, 'colocada sobre seus pés' e, ligada a ela, a inserção do agir consciente como autor coadjuvante no impulso revolucionário, irrefreável. A astúcia da razão coincide finalmente com a vontade dos atores (JONAS, 2006, p. 214)". Porém, ressalva que "pela primeira vez, se inscreve no mapa ético, sob o signo da dinâmica, a responsabilidade pelo futuro bistórico, de forma racionalmente inteligível (JONAS, 2006, p. 214)." Contudo, o problema da constatação da escatologia histórica jonasiana é a ausência de contexto histórico-político-social, como se a ideia de bem platônica ou a ideia reguladora kantiana brotassem por geração espontânea, independente das crises significativas ocorridas, desde o século XII até meados do XVII, a exigirem mudanças no campo religioso, político, científico, técnico, conduzidas, grosso modo, pela nascente acumulação de riqueza e a vindoura ordem do capital. Ao fim do processo dinâmico, foram-se de roldão, após sucessivas metamorfoses, o imaginário acerca da cidade de Deus e o ethos antigo. No mesmo passo, ideias-força modernas adentraram à cena: as matemáticas, como escola rigorosa do pensamento; "a verdade efetiva das coisas" para o conhecimento dos fatos da política, não mais as idealizações; a necessidade de método científico experimental para o conhecimento das leis intrínsecas da natureza; a separação entre teologia e filosofia e, por fim, a utopia, quiçá para o lugar decaído da cidade de Deus.

Contudo, ainda refletindo acerca da chave escatológica da história, Jonas intenciona atualizar a constatação, registrando: 
Com a tomada do poder por parte da tecnologia (uma revolução incontrolável, que não foi planejada por ninguém e é inteiramente anônima) (sic), a dinâmica ganhou novos aspectos, que não estavam incluídas em nenhuma das suas representações feitas antes, e, que nenhuma teoria, inclusive a marxista, poderia haver previsto - uma direção que, em vez de conduzir à sua plena realização, poderia conduzir à catástrofe universal, em um ritmo cuja aceleração exponencial, assustadora, ameaça fugir a qualquer controle (JONAS, 2006, p. 214-215)."

Mas, dada a pausa de lucidez para não acusar o horizonte marxista, Jonas desliza implacável para o platô de créditos acumulados: “Certamente, não podemos mais confiar em nenhuma 'razão da história' imanente, e seria pura frivolidade falarmos de um 'sentido' autorrealizável dos acontecimentos (JONAS, 2006, p. 215).” Logo, se deve acreditar em quê? Há uma volatilidade de substrato dramático na filosofia jonasiana, mais patenteada na parte final de sua obra magna. Os dois últimos capítulos parecem retratar uma certa angústia do Filósofo ao optar pelo horizonte marxista, para garantia da preservação da natureza, dentre outros motivos. Porém, com tantas ressalvas e contrapesos, que finda por praticamente inocular a opção, em vista do nada seguro liberalismo. O suposto desassossego o leva, por vezes, para o discurso às margens de um tom panfletário a descaracterizar o marxismo e, por consequência, a utopia concreta de Bloch. O resultado sugere o efeito contrário, os alvejados saem fortalecidos, como se verá, ao menos em parte.

Não obstante prescindindo do caráter escatológico da história, alguns temas análogos, aos interposto por Jonas, não escaparam a Bloch, sob análise detalhada ao cuidar do "conteúdo último do desejo e o bem supremo", desde os nexos entre "pulsão e alimento", às "imagens de valores como variações do bem supremo", de Platão e Cícero a Kant, retornando aos nexos entre pulsão e alimento ou subjetividade, em vista dos valores e do bem supremo, para além do primeiro a ser cumprido que é o comer, depois, a moral, como apontara Jonas (BLOCH, III, 54, p. 396-339). Para Bloch, a pulsão de fome é a mais primitiva e pauta o desejo (BLOCH, III, $)^{8}$.

\footnotetext{
${ }^{8}$ De uma conversa com Anderson Alves Esteves: certamente, para a questão da pulsão da fome, Bloch pode ter se inspirado em passagem marxiana dos Manuscritos Econômicos-Filosóficos 1844. Eis a passagem a ilustrar: "O homem é imediatamente ser natural. Como ser natural, e como ser natural vivo, está, por um lado, munido de forças naturais, de forças vitais, é um ser natural ativo; estas forças existem nele como possibilidades e capacidades (Anlagen und Fähigkeiten), como pulsões; por outro lado, enquanto ser natural, corpóreo, sensível, objetivo, ele é um ser que sofre, dependente e limitado, assim como o animal e a planta, isto é, os objetos de suas pulsões existem fora dele, como objetos independentes dele. Mas esses objetos são objetos de
} 
Jonas principia o item "A ameaça tenebrosa contida no ideal baconiano", afirmando que "sob a pressuposição de que vivemos em uma situação apocalíptica, às vésperas de uma catástrofe, caso deixemos que as coisas sigam o curso atual" de progresso desenfreado. Para apontar a causa subjacente ao colapso da natureza, escreve que o "perigo decorre da dimensão excessiva da civilização técnico-industrial, baseada nas ciências naturais" e, apoiado em reflexão anterior, afirma que o chamado "projeto baconiano [...] não contou desde as origens, na sua execução capitalista, com a racionalidade e a retidão que lhe seriam adequadas (JONAS, 2006, p. 235)". Porém, a constatação não é novidade, pois, de certa forma, fora antecipada por Husserl, em Krisis, de 1937, (HUSSERL, 2002) e mostrada, no detalhe, por Adorno e Horkheimer, em a Dialética do Esclarecimento, de 1944. Mas Jonas não esclarece qual racionalidade e que retidão foram requeridas para aquela tarefa, mesmo assim prossegue afirmando que

sua dinâmica de êxito, que conduz obrigatoriamente (sic) aos excessos de produção e consumo, teria (- tempo verbal, futuro pretérito simples -) subjugado qualquer sociedade, considerando-se a breve escala de tempo dos objetivos humanos e a imprevisibilidade real das dimensões do êxito (JONAS, 2006, p. 235).

Uma vez que, prossegue Jonas, a "ameaça de catástrofe do ideal baconiano de dominação da natureza por meio da técnica reside, portanto, na magnitude do seu êxito." E o aludido "êxito tem duplo aspecto: econômico e biológico. A inter-relação de ambos, que conduz necessariamente à crise, é hoje patente (JONAS, 2006, p. 235)." Abreviando, sob a iminência de "uma catástrofe aguda da humanidade e da natureza", pelo "crescimento de uma única espécie", empobrecida, que lutará pela sobrevivência crua (JONAS, 2006, p. 236). Ao que comenta: "É com pavor que imaginaríamos as

seu carecimento (Bedürfnis), objetos essenciais, indispensáveis para a atuação e confirmação de suas forças essenciais. Que o homem é um ser corpóreo, dotado de forças naturais, vivo, efetivo, objetivo, sensível significa que ele tem objetos efetivos, sensiveis como objeto de seu ser, de sua manifestação de vida (Lebensäusserung), ou que ele pode somente manifestar (äussern) sua vida em objetos sensíveis efetivos (wirklich sinnliche Gegenstände). É idêntico: ser objetivo, natural, sensível e ao mesmo tempo ter fora de si objeto, natureza, sentido, ou ser objeto mesmo, natureza, sentido para um terceiro. A fome é uma carência natural; ela necessita, por conseguinte, de uma natureza fora de si, de um objeto fora de si, para se satisfazer, para se saciar. A fome é a carência confessada de meu corpo por um objeto existente (seienden) fora dele, indispensável à sua integração e externação essencial. O sol é o objeto da planta, um objeto para ela imprescindível, confirmador de sua vida, assim, como a planta é objeto do sol, enquanto externação da força evocadora de vida do sol, da força essencial objetiva do sol (MARX, 2004, p. 127)." 
mortes e os assassinatos em massa, que acompanhariam uma situação como essa”. Eis o quadro que, para ele, trata-se de um imenso "desafio especular (de) como será possível que aquela parte da humanidade (sobrevivente), [...], seguirá vivendo em uma Terra devastada (JONAS, 2006, p. 236)" 9 . Tema atualíssimo para o tempo da pandemia do Covid-19, antecipado pela reflexão: “'O poder', como força final e causal, se distribui por todo reino vivo. Grande é poder de tigres e elefantes, maior o dos cupins e gafanhotos, maior ainda o das bactérias e vírus (JONAS, 2006, p. 216).”

Ao referir-se aos marxistas, o Filósofo da Responsabilidade afirma que

podem rebater nossas considerações prévias sobre a utopia com dois argumentos: o primeiro é o que ignoramos a revolução e, consequentemente, não levamos em conta a novidade sem precedentes que a revolução introduz na equação humana, tornando inválidas as analogias com o passado. (...) Em segundo lugar, ela (a revolução) criará condições tão novas pra a existência humana e tão libertadoras do potencial humano até hoje reprimido, que se torna impossível qualquer comparação com o passado, desvanecendo-se toda história até agora em uma pré-história (JONAS, 2006, p. 282).

Em verdade, Jonas abrevia o que escrevera, anteriormente: “Toda história até agora é a pré-história do homem verdadeiro, como ele pode e deve ser (JONAS, 2006, -239)". O Filósofo parece glosar a passagem final de o "Prefácio", da Contribuição à Crítica da Economia Política, de 1859: "Com esta formação social termina, pois, a préhistória da sociedade humana (MARX, 1946, p. 32)"10. Ao que acrescenta:

\footnotetext{
9 "Terra devastada", expressão que relembra o título e, quiçá, o espírito do poema homônimo de Eliot, The Last Land, de 1922. Na tradução, o título ficou: "A terra desgastada" ou "A terra gasta", em duas variáveis. Contudo, o poema foi escrito ao tempo do rescaldo - cinza que contém brasa - sob os dissabores da Primeira Guerra Mundial. Eis a segunda estrofe do poema "I - O enterro dos mortos", versos 20-27, que ocorre ser ilustrativa para a provável referência jonasiana: "Que raízes brotam, que ramos grimpam / Desse entulho pedregoso? Filho do homem, / Dizer ou supor não podes, só conheces / Um feixe de imagens quebradas batidas de sol; / E a árvore morta não dá asilo, o grilo, alívio / E a pedra seca nenhum murmúrio de água. / Há sombra apenas sob essa rocha vermelha, / (Vem para a sombra da rocha vermelha), / E te mostrarei qualquer coisa diferente / Da sombra que atrás de ti caminha de manhã / Ou da que à tarde se ergue ao teu encontro; / O medo mostrarei em um punhado de pó (ELIOT, 1980, p. 35)." - No original, "I - The burial of the dead", versos 20-27: "What are the roots that clutch, what branches grow / Out of this stony rubbish? Son of man, / You cannot say, or guess, for you know only / A heap of broken imagens, where the sun beats. / And the dead tree gives no shelter, the cricket no relief, / And the dry stone no sound of water. Only / There is shadow under this red rock, / (Come in under the shadow of this red rock), / And I Will show you something different from either / Your shadow at morning striding behind you / Or your shadow at evening rising to meet you; / I will show you fear in a handful of dust (ELIOT, 1980, p. 34)."

${ }^{10}$ Outra frase próxima da referida no "Prefácio", é a que consta de Crítica do Programa de Gotha. Ei-la: "Essa é lei de toda a história até o presente" (MARX, 2012, p. 25).
} 
Abstraindo a crença vaga sobre o progresso moral da humanidade graças à civilização, que não define um programa de ação [...], existem duas formas prático-prescritivas do ideal: em primeiro, aquela já comentada forma baconiana de poder crescente sobre a natureza; em seguida, tendo isso como pressuposto, a forma marxista da sociedade sem classes. Porém, só o programa marxista, que integra a ingênua fórmula baconiana de dominação da natureza e de transformação radical da sociedade, esperando, com isso o surgimento do homem definitivo, pode ser hoje considerado seriamente como fonte de uma ética que oriente a ação predominantemente para o futuro, daí extraindo suas normas para o presente (JONAS, 2006, p. 239).

Com fôlego, Jonas considera "o marxismo como executor do ideal baconiano". Contudo, com pretensa ironia faz recair a incidência do projeto baconiano por cima do marxismo ou comunismo, — identidade equivocada nos termos - , e nas pessoas dos seus executores. Ora, séculos antes do regime soviético, - que significa regime de conselhos —, existir, o Ocidente apropriou-se de modo cabal da concepção baconiana de ciência e de técnica, que são os fatores do progresso desenfreado, conjugados e arrematados à lógica do capital. Para Jonas, o progresso "gera novos problemas para resolver os problemas que ele mesmo cria, tornando-se sua própria compulsão" (JONAS, PR, p. 291). Assim, como pôde o regime comunista, filtrado erroneamente do pensamento político de Marx, figurar responsabilizado pela incorporação e prática do projeto baconiano? - O pessimismo jonasiano move-se à caça de transgressores.

Se o argumento anti-utópico jonasiano encontra-se disseminado por, praticamente, todo O Princípio Responsabilidade. Porém, nos Capítulos V e VI da obra aparecem as críticas pontuais ao utopismo de matriz marxista, atualizado e expressado por Bloch, em O Princípio Esperança. No mesmo passo, Jonas concebe o marxismo caracterizado por "teoria especulativa” (JONAS, PR, p. 195), “escatologia viva” (p. 239), deste modo, “o ‘marxismo', como tal, não passa de uma abstração” (PR, p. 251), ao passo que concebe também a utopia marxista como "escatologia secularizada e herdeira da religião (p. 287), além de considerar que "o marxismo é um dos frutos do pensamento baconiano. Ele se compreende, fundamentalmente, como aquele que foi escolhido para ser o se executor testamenteiro (JONAS, 2006, p. 254).” Porque "Desde o início o marxismo celebrou o poder da técnica, acreditando que a salvação 
dependesse da união desta com a socialização (JONAS, 2006, p. 254)", 11 certamente, reiterar a linha do nexo entre religião cristã e marxismo, desde o caráter salvífico de ambos.

Por outra mão, para uma questão pretérita, Jonas propõe: “Temos de examinar os regimes marxistas concretos e os partidos comunistas concretos” (JONAS, PR, p. 251). Questão grave, talvez ignorada por Jonas: onde existiram "regimes marxistas concretos”? Certamente, não é o que pensa Mészáros, marxista de pensamento denso, ao fazer a crítica do socialismo real existente, de um ponto de vista de esquerda, filosoficamente, fundamentada em Hegel e em Marx, além de Lukács.

Em o item "A crítica da utopia e a ética da responsabilidade", (JONAS, 2006, p. 287 ss.), Jonas parece descrever a parábola do fim dos tempos. Porém, antecipada da constatação grave:

A maior das tentações reside na alma do marxismo - a utopia. Essa é a sua tentação mais nobre e por isso mais perigosa. Pois naturalmente ela não consiste no 'materialismo' da explicação marxista da história e mesma na sua ontologia simplista de um conteúdo banal e material do seu ideal, ou seja, o ideal dos estômagos cheios. (Pois) O materialismo refere-se às condições, não aos fins. No lema 'primeiro vem o comer, depois a moral' (JONAS, 2006, p. 256-257).

A frase fora retirada de a Ópera dos três vinténs, de Bertold Brecht, e, por certo, parodiada por Dom Helder Câmara, a meados dos anos 60 do século passado: "Primeiro alimentar, depois evangelizar". Jonas insiste no raciocínio:

deve-se levar a sério tanto a palavra 'primeiro' quanto a 'depois'. Isso significa que os famintos (ameaçados de morrer de fome), bem como aqueles que estão sendo sufocados, são privados das necessidades mais básicas da vida, e, por isso, mantidos em um estado pré-moral; mas, 'em seguida', efetivamente 'vem a moral', que reivindica o seu quinhão (JONAS, 2006, p. 257).

Por certo, um juízo precipitado. Para Jonas,

${ }^{11}$ Comentário lateral. Os primeiros escritos de Engels, parceiro intelectual de Marx, apontam para o contrário do que afirma Jonas. Pois, tanto em o Esboço para uma crítica da economia política (1844) (ENGELS, 1979, pp. 1-29), como em A situação da classe trabalhadora na Inglaterra (1845), em particular, no Capítulo "Os diferentes ramos da indústria: os operários de fábrica propriamente dito" (ENGELS, 1973, pp. 170-237), o Filósofo mostra as implicações devastadoras das máquinas na indústria de tecelagem para o proletariado, em particular, e para o tecido social, de modo geral. O primeiro texto, um artigo publicado na Revista Anais Franco-Alemães, em fevereiro de 1844, influenciou Marx na pesquisa da economia política, base crítica de $O$ Capital. 
a insolente banalidade que parece relativizar 'a moral' (algo a que só alguns podem se dar ao luxo) estipula, na verdade, ela própria, um dever moral para com terceiros, ou seja, ajudar a superar uma condição que inviabiliza a moral, substituindo por outra situação na qual não se possa dizer: 'as circunstancias não o permitem' (JONAS, 2006, p. 257).

A certa altura de O Princípio Responsabilidade, Jonas deixa transparecer o incômodo latente, não desvelado, acerca das possibilidades da utopia concreta, sobretudo no tocante à superação da sociedade de classes, que parece desaprovar, e a consequente transformação do mundo do trabalho, se cumprido o encetamento de distribuir a cada trabalhador segundo a sua necessidade. Comentado, lateralmente, pelo Papa Pio XI, na encíclica Quadragesimo $A n n o^{12}$, de 1931, à sua vez comentando a encíclica Rerum Novarum. De modo a promover a ideia de reformar o capitalismo para evitar revoluções socialistas. Afinal, se o trabalhador participar do lucro da empresa, estará "roubando" a si mesmo, recebendo o mais-valor que, supostamente, concordou em deixar desapropriar-se. Mas, o incomodo maior para Jonas pode ser o ócio, aquele sonhado pelos filósofos desde a Antiguidade, porém, de modo compulsório melhor distribuído para todos os homens. Ócio que é o contrário do lazer programado. Jonas imagina uma sociedade utópica plena de homens desocupados, talvez advinda de algumas das recorrências ilustrativas, frutos da

12 Ilustrando. "Ora nem toda a distribuição dos bens ou riquezas entre os homens é apta para obter totalmente ou com a devida perfeição o fim estabelecido por Deus. E necessário que as riquezas, em contínuo incremento com o progresso da economia social, sejam repartidas pelos indivíduos ou pelas classes particulares de tal maneira, que se salve sempre a utilidade comum, de que falava Leão XIII, ou, por outras palavras, que em nada se prejudique o bem geral de toda a sociedade. Esta lei de justiça social proíbe, que uma classe seja pela outra excluída da participação dos lucros. Violam-na por conseguinte tanto os ricos que, felizes por se verem livres de cuidados em meio da sua fortuna, têm por muito natural embolsarem eles tudo e os operários nada, como a classe proletária que, irritada por tantas injustiças e demasiadamente propensa a exagerar os próprios direitos, reclama para si tudo, porque fruto do trabalho das suas mãos, e combate e pretende suprimir toda a propriedade e rendas ou proventos, qualquer que seja a sua natureza e função social, uma vez que se obtenham e pela simples razão de serem obtidos sem trabalho. A este propósito cita-se às vezes o Apóstolo, lá onde diz: 'quem não quer trabalhar, não coma'. Citação descabida e falsa. O Apóstolo repreende os ociosos, que podendo e devendo trabalhar, não o fazem, e admoesta-nos a que aproveitemos diligentemente o tempo e as forças do corpo e do espírito, nem queiramos ser de peso aos outros, quando podemos bastar-nos a nós mesmos. Agora, que o trabalho seja o único título para receber o sustento ou perceber rendimentos, isso não o ensina, nem podia ensinar o Apóstolo ( $\mathrm{PIO}$ XI, Princípio diretivo da justa distribuição", 1931)." Disponível em: http://w2.vatican.va/content/piusxi/pt/encyclicals/documents/hf_p-xi_enc_19310515_quadragesimo-anno.html. Acesso em: 21 set. 2019. 
reflexão blochiana registrada em "Jornada de oito horas, mundo em paz, tempo livre e lazer" (BLOCH, II, 42, p. 437-477).

Oportuno notar, que à nota 17, p. 332-333, de O Princípio Responsabilidade, Jonas refere-se à "utopia de Herbert Marcuse, que, baseando-se na teoria freudiana das pulsões, defende que o princípio do prazer se libertaria do princípio da realidade.” Em verdade, pela dialética, Marcuse intenciona criticar e superar a posição freudiana, pois, firma suas crítica e concepção para além do biologista e neurólogo Freud. Jonas cita passagem de Eros e Civilização ao registrar:

Já que a duração da jornada de trabalho constitui um dos principais fatores para a substituição do princípio do prazer pelo princípio de realidade, a redução do tempo de trabalho, até um ponto em que a quantidade de trabalho não impeça mais $O$ desenvolvimento humano, é a primeira condição de liberdade. [...] A esfera além do trabalho despendido é a que caracteriza a liberdade e a satisfação, e é a definição da existência humana dessa esfera que constitui a negação do princípio do desempenho.

Para concluir que "Alguns trechos dessa citação mostram a coincidência completa com Marx e Bloch — o delírio intelectual, contra o qual esta crítica se dirige (JONAS, n. 17, p. 332-333).” O comentário é exterior e não atinge a proposta marcusiana de uma civilização libidinal. Coisa gravíssima, pecaminosa no limite, para um neófito em realismo mundano ${ }^{13}$.

Digressão. $\mathrm{Na}$ linha da decolonização antropofágica, nos anos 40 do século passado, Oswald de Andrade, em A Marcha das Utopias, meditou:

O ócio fora também, em todas as religiões, tido como um dom supremo, particularmente, pelo sacerdócio, detentor de ócio sagrado que distingue e enobrece os mediadores de Deus. Na vida futura, é ele, o ócio, a recompensa das penas e atribuições que sofremos neste mundo. Não está longe dos prazeres fantásticos prometidos por outros cultos, esse que para os cristãos é a alegria suprema da contemplação beatífica de Deus - Ócio puro (ANDRADE, 1970, p. 158).

Se Oswald de Andrade parece antecipar Marcuse na tese acerca da civilização libidinal, porém, sem Deus, em verdade, segundo Furter, Oswald precipita, de certa

\footnotetext{
${ }^{13}$ Para compreensão da concepção de civilização libidinal, em Marcuse, ver ESTEVES, A. A. "Nova sensibilidade e socialismo integral", In: ESTEVES, A. A. Do Socialismo Científico ao Socialismo Utópico: o projeto emancipatório de Herbert Marcuse - política e estética nas décadas de 1960 e 1970, Curitiba: CRV, 2020. p. 244-275.
} 
forma, o achado da filosofia da esperança de Bloch. Para Furter, "surpreendente é o encontro entre o ‘orfismo cósmico’ e as dimensões cósmicas da esperança bloquiana. Também no artigo de 2 de agosto, Oswald lança uma fórmula singular que poderia muito bem repercutir na obra de Bloch de um 'ateísmo com Deus' (FURTER, 1974, p. 71)."

Retomando. De outro lado, Jonas parece não ter assimilado, no detalhe, a distinção entre o positivismo e o hegelianismo, particularmente, em relação à categoria da negatividade, em Hegel, marca fundamental de sua filosofia, contrária ao antípoda positivista. Se pode ler em Razãa e Revolução: o advento da teoria social em Hegel, de Marcuse, publicado em 1941, o modo como se deu a vitória do positivismo. E a categoria da negatividade é a chave basilar e de entrada para compreensão da filosofia de Marx. Em verdade, Jonas, pretendendo-se crítico da corrente científica desde Bacon, parece ignorar o lastro arraigado do positivismo solidificado e consolidado nas interpretações filosóficas contemporâneas. Afinal, historicamente, o positivismo venceu a filosofia dialética negativa de Hegel. Por consequência, o mundo presente é o da vitória do neopositivismo, da filosofia analítica e congêneres. Ora, por que Jonas não adentra este problemático aspecto da filosofia contemporânea e volta sua crítica para o marxismo e a utopia concreta de Bloch? Aparenta mover sua mira crítica para o falso inimigo, desconcertado. Por certo, o verdadeiro inimigo da Filosofia dialética negativa é o positivismo em derivações por várias frentes filosóficas.

Afinal, o regime soviético, se em seus primórdios ensaiou transformar-se como tal firmando-se desde os soviets, porém, de fato nunca chegou a ser plenamente um regime socialista, em substância, como quer Mészáros ${ }^{14}$. Transformou-se aos poucos em regime falimentar, fechou para balanço o ensaio de utopia e não abrirá mais as portas. Aliás, aparentemente, em nenhum lugar do mundo. Talvez o espírito e a prática conselhista operária ${ }^{15}$ possam se metamorfosear em um regime libertário de autogestão, no futuro. A título de provocação, Jonas não se refere, nominalmente, a Auguste Comte em nenhuma passagem de sua magna obra. Todavia, refere-se a Marx

\footnotetext{
${ }^{14}$ A propósito, ver MÉSZÁROS, I. "Política Radical e Transição para o Socialismo" (MÉSZÁROS, 2011, p. 1063-1078).

${ }^{15}$ Os conselhos foram objeto de análise e projeção política revolucionária por Anton Panneköek, Gramsci, Debord, e de registro das ações conselhistas, ocorridas durante a Guerra Civil Espanhola, por Diego Abad de Santillán, em de El organismo económico de la revolución (1936).
} 
em treze páginas. E a Bloch, por vinte e duas. Porém, Bloch, salvo melhor juízo, nunca se referiu a Jonas.

Em verdade, ao que tudo indica, Jonas pretende desidratar o marxismo, tornálo sem instinto, retirando-lhe o seu caráter utópico, segundo a sua concepção. A rigor, a pretensão é retirar o caráter histórico do marxismo, sua base histórica científica. Afinal, para Marx, tudo é história, pois, História é a ciência que contém todas as outras, referidas a ela. Contudo, Jonas reconhece, racionando em semicírculo, que

o marxismo, 'progressista' na origem, nascido sob o signo do 'princípio esperança' (- por certo, em concessão à filosofia de Bloch -), e não sob o 'princípio do medo', (- em referência ao Pai do medo em filosofia política? -), é tão tributário do ideal baconiano quanto a sua contraparte capitalista." Uma vez que "a lógica que comanda o projeto socialista é igualar e depois ultrapassar o capitalismo na coleta dos frutos obtidos graças à técnica.

Raciocínio equivocado, pois a filosofia política marxista pretende liquidar a propriedade privada, a divisão social do trabalho, o estranhamento do trabalho, o Estado e as classes sociais, aos moldes do que fora ensaiado durante a Comuna de Paris. De modo a não competir com o modo de produção capitalista, mas liquidá-lo". E volta à carga, “o marxismo é, quanto à sua origem, um herdeiro da revolução baconiana, compreendendo-se como seu testamenteiro - aliás, como melhor testamenteiro do que o capitalismo, pois mais eficiente (JONAS, 2006, p. 241).”

Porém, o marxismo é tributário do Idealismo Alemão, basicamente, da filosofia de Hegel, dos economistas liberais ingleses, e da generosidade do socialismo utópico francês. Ultimamente, aditado de raízes românticas e do espírito da ciência moderna. Rebaixá-lo a testamenteiro da utopia baconiana é desconhecer sua ampla base filosófica, histórica, econômica, literária e utópica, para além da utopia $A$ Nova Atlântida, de Bacon. Assim, compreendido o marxismo ficará muito diferente, irreconhecível, garante Jonas (JONAS, 2006, p. 241). Porém, para um marxismo emasculado, Jonas, afinal, não apresenta a caricatura correspondente. O raciocínio jonasiano tem sido, por certo, a mostra falsificada do que é e do que tem sido o marxismo, continuado por Bloch, Lukács, Karl Korsch, Gramsci, Sartre, Marcuse, bem e mal por Althusser, Mészáros, dentre outros, de modo a atualizar-se e completar-se conceitualmente. Além de enfrentar, explicitar e diagnosticar as suas 
crises, desde 1918, ao momento da publicação de O Espirito da Utopia, de Bloch, seguido de História e Consciência de Classe, de Lukács, de 1923, e de Filosofia e Marxismo, de Karl Korsch, do mesmo ano. Assim, 1923 tornou-se o marco da discordância dos jovens filósofos com a apropriação de ordem positivista da filosofia marxiana, cujos efeitos de baixo relevo apareceram estampados nos ditames da $2^{\text {a }}$ Internacional. E outra crise perspectivada, externamente, ao âmbito marxista, por Merleau-Ponty, em As Aventuras da Dialética, de 1955, — talvez por desavença pessoal com Sartre.

Jonas parece não entender o marxismo, principalmente, sua fundamentação histórico-filosófica. Marxismo é o corte na Filosofia, a ruptura na tradição filosófica. O que equivale a dizer que a Filosofia caminhou até Hegel, e de Hegel para Marx. Porque, segundo Bloch, depois que todos os grandes pensadores anteriores a Marx haviam se contentado, essencialmente, com um devir filosófico do mundo restrito ao livro, tem início de fato, no horizonte do espírito humanitário marxista, suo modo, uma secularização da filosofia. De tal modo que ela é colocada totalmente sobre os seus próprios pés e assim se mostra tão vocacionada quanto apta a trabalhar na reconstrução da estrela chamada Terra (BLOCH, III, 55, p. 451).

Afinal, para Bloch, "El marxismo, por tanto, no es una utopia, sino el novum de una utopia concreta. [...] (Reiterando), el marxismo no es que no sea una utopia, sino que es una utopia concreta (BLOCH, 1980, p. 64)". E a utopia concreta fundase na ontologia do "ainda-não-consciente", ambas derivadas da docta spes, como referido. Recorrendo a Kant, relembra que ao final de Sonhos de um visionário, lê-se o lema: "Esperança e futuro". Para concluir que "Nunca habrá, por ello, suficiente utopía concreta (BLOCH, 1980, p. 65-66)" "16.

Bloch sintetiza, lastreado no materialismo utópico, se o medo anula o humano, a esperança apenas transcende o horizonte, ao passo que o conhecimento do real mediante a práxis o desloca de maneira sólida; ainda assim, é exclusivamente a esperança que conduz à compreensão de mundo estimulante e consoladora e permite obtê-la; ao mesmo tempo, como a compreensão mais sólida e mais tendencialmente concreta.

Contudo,

\footnotetext{
${ }^{16}$ Trata-se da publicação póstuma de conferências pronunciadas na Universidade de Tübingen, durante o Inverno de 1965, intitulada Despedida de la utopía?
} 
o consolo da compreensão do mundo necessita ser, penosamente, elaborado em conjunto. [...] (É que) A razão não consegue florescer sem esperança, a esperança não consegue falar sem a razão, ambas associadas numa unidade marxista - qualquer outra ciência é sem futuro, qualquer outro futuro é sem ciência (BLOCH, III, 55, p. 453).

Contudo, Jonas, em diversas passagens de O Princípio Responsabilidade, esforçase por defender o modelo liberal, em detrimento do marxismo. Embora optando pelo marxismo, identificado ao comunismo, na defesa e preservação futuras da natureza, por diversos motivos (JONAS, 2006, p. 239-250) ${ }^{17}$. Futuro que não existe mais, dado o fim do regime execrado por Jonas. Em verdade, Jonas é um liberal no sentido clássico do termo. Ocorre que o liberalismo tem fornecido, em essência, o modelo de revisionismo histórico para guerra e revolução ${ }^{18}$. Àquela interrogação acerca de Jonas, ao final da palestra do Prof. Paolo Becchi, durante o Colóquio, de 2016, se acaso Jonas é um pensador conservador ou não, remete ao espectro do revisionismo histórico, em paralelo. Hoje, tende a esclarecer-se a posição de que é um liberal, próximo da apropriação da doutrina pelos norte-americanos, devendo menos à filiação doutrinária europeia. O que, consequentemente, traz implicações e acomodações impossíveis de ver claro o que tem sido o marxismo e o que foi o regime comunista. O filtro liberal transtorna a visão, pois liberalismo e marxismo são inconciliáveis. O que deve valer para ambas visões de mundo, como as que distingue Horkheimer, em Eclipse da Raz̃ão.

Contudo, se tivesse Jonas compreendido a filosofia de Hegel de modo mais profundo, como transparece em O Princípio Responsabilidade, reconheceria que o liberalismo, enquanto visão de mundo, já cumpriu suas premissas, — da liberdade econômica, liberdade política e liberdade de expressão. Assim, cumpridas as premissas, deve encontrar-se em movimento a necessidade histórica de invenção de uma nova concepção de liberdade, que não cancele as aquisições anteriores,

\footnotetext{
17 "Schoefs (2009) identifica cinco razões, elencadas por Jonas, pelas quais o marxismo parece mais habilitado a lidar com o risco inerente à técnica do que a democracia de regime liberal...", CARVALHO, H. B. A. de; ALMEIDA, L. M. F. "Marxismo", In: OlIVEIRA, J.; POMMIER, E. (Orgs.), Vocabulário Hans Jonas, Caxias do Sul, EDUCS, 2019. p. 140.

${ }^{18}$ A propósito, conferir LOSURDO, D., Guerra e Revolução: o mundo um século após Outubro de 1917, tradução Ana Maria Chiarini e Diego Silveira Coelho Pereira, São Paulo, Boitempo, 2017. Ver também TOLEDO, I. A. de M. "O revisionismo histórico e a liquidação da tradição revolucionária". Projeto História, S. Paulo, v. 60, p. 351-357, out-dez. 2017. (Resenha do livro de Losurdo).
} 
consolidadas, mas que, desde a provável síntese lançada para a plataforma superior, alcance os princípios do que será a próxima etapa da História. Afinal, pensando hegelianamente, tudo que está firmado, está para ser negado, embora haja uma parálise da crítica e a síntese das contradições em curso pareça demorar a se manifestar. Coisa que, provavelmente, os filósofos do liberalismo não conseguirão atingir, nem compreender. Caso contrário, acaso o propalado fim da História encontra-se em movimento?

Concluindo, Jonas mostra-se convincente na fundação teórica do princípio responsabilidade para a civilização tecnológica, e para todas as iminentes decorrências do progresso científico-tecnológico. Porém, pouco persuasivo em a crítica da utopia concreta, de matriz marxista, sob a concepção de Bloch. Tarefa áspera a de denegar a utopia seja qual for, porque improvável, uma vez que a humanidade desde os paraísos perdidos e as ilhas paradisíacas dos estoicos sonha com seus retornos, para além do recalque inconsciente. Cristóvão Colombo e praticamente todos os conquistadores da América estiveram imbuídos de um largo espírito edênico, de par com a volúpia da cobiça do ouro, de pedras preciosas, da luxúria e, do seu par complementar, da tristeza, segundo Paulo Prado, em Retrato do Brasil.

Entretanto, para Enzo Traverso,

Resumindo, a virada do século coincidiu com uma transição do 'princípio esperança' para o 'princípio responsabilidade'. O 'princípio esperança' inspirou as lutas do século passado, de Petrogrado em 1917 a Manágua em 1979. [...] O 'princípio responsabilidade' surgiu quando o futuro ficou turvo, [...] quando a ecologia nos conscientizou dos perigos que ameaçam o planeta e começamos a pensar que tipo de mundo queremos deixar para as gerações futuras (TRAVERSO, 2018, p. 38).

Afinal, o próprio Jonas ajuizara:

E basta desse tipo de especulação. Entretanto, já se terá observado que essas considerações têm pouco a ver com o conteúdo essencial do marxismo. Elas levam em conta apenas certas propriedades formais de sua realidade histórica, que poderiam servir eventualmente à incerta tarefa de salvaguardar o futuro. $O$ autor está preparado para ser acusado de cinismo e não deseja rebater essa acusação com garantias de ter boas intenções." (JONAS, 2006, p. 247-248).

No entanto, contraditoriamente, Jonas raciocina e escreve como um liberal, pendulando entre o liberalismo social e o conservador, porém, mostrando-se um 
liberal de talhe pessimista, num ponto equidistante da linhagem reformista conservadora de Rawls, de Hannah Arendt e de outros ${ }^{19}$.

\section{Referências}

ABAD DE SANTILLÁN, D. El Organismo Economico de la Revolución. Bilbao/Madrid: Zero/ZYX, 1978.

ANDRADE, O. "A marcha das utopias", In: ANDRADE, O. Do pau-brasil à antropofagia e às utopias, $2^{a}$ edição. Rio de Janeiro: Civilização Brasileira, 1970. p. 145-200.

BLOCH, E. O Princípio Esperança, tradução Nélio Schneider. vol. I. Rio de Janeiro: Contraponto / EdUERJ, 2005.

BLOCH, E. Das Prinzip Hoffnung. v. 1. Berlin: Aufban-Verlag, 1960.

BLOCH, E. Das Prinzip Hoffnung -Gesamtausgabe in 16 Bänden Band 5. Kapitel 1-32. Frankfurt am Main: Suhrkamp Verlag, 1977.

BLOCH, E. O Princípio Esperança. Trad. Nélio Schneider. v. II. Rio de Janeiro: Contraponto / EdUERJ, 2006.

BLOCH, E. O Princípio Esperança, tradução Nélio Schneider. vol. III. Rio de Janeiro: Contraponto / EdUERJ, 2006a.

BLOCH, E. Despedida de la Utopía? Trad. Sandra Santana Pérez. Madrid: A. Machado, 1980.

ELIOT, T. S. Poemas 1910-1930. Trad. Idelma Ribeiro de Faria. São Paulo: Hucitec, 1980.

ENGELS, F. "Esboço para uma crítica da economia política". Revista Temas de Ciências Humanas, São Paulo, n. 5, pp. 1-29, 1979.

ENGELS, F. A Situação da Classe Trabalhadora em Inglaterra. Trad. Analia C. Torres. Porto: Afrontamento, 1973.

ESTEVES, A. A. Do Socialismo Científico ao Socialismo Utópico: o projeto emancipatório de Herbert Marcuse - política e estética nas décadas de 1960 e 1970. Curitiba: CRV, 2020.

FURTER, P. Dialética da Esperança: uma interpretação do pensamento utópico de Ernst Bloch. Rio de Janeiro: Paz e Terra, 1974.

HUSSERL, E. A Crise da Humanidade Européia e a Filosofia (Krisis). 2. ed. Trad. Urbano Zilles. Porto Alegre: EDIPUCRS, 2002.

\footnotetext{
${ }^{19}$ Jonas parece operar sob um tipo de transformação conservadora, pela ação de reformar para não mudar, como na fala de Don Fabrizio Corbera, Príncipe de Salina, Sícilia, personagem do romance Il Gattopardo, de Guiseppe Tomasi di Lampedusa, 1954, ao retratar os impasses do II Risorgimento, ao tempo da unificação da Itália, a meados do século XIX.
} 
JONAS, H. O Princípio Responsabilidade: ensaio de uma ética para a civilização tecnológica. Trad. Marijane Lisboa e Luis Barros Montez. Rio de Janeiro: Contraponto/PUC-Rio, 2006.

JONAS, H. Das Prinæip Verantwortung: Versuch einer Ethik für die technologische Zivilisation. Frankfurt: Suhrkamp, 2003. (tascehnbuch).

LAMPEDUSA, G. T. Il Gattopardo. Milano: Feltrinelli, 2002. (Collana: Le Comete).

LOSURDO, D. Guerra e Revolução: o mundo um século após Outubro de 1917. Trad. Ana Maria Chiarini e Diego Silveira Coelho Pereira. São Paulo: Boitempo, 2017.

MARX, K. Crítica do Programa de Gotha. Trad. Rubens Enderle. São Paulo: Boitempo, 2012.

MARX, K. "Prefácio". In: MARX, K. Contribuição à Crítica da Economia Política. Trad. Florestan Fernandes. São Paulo: Flama, 1946.

MARX, K. Manuscritos Econômico-Filosóficos (1844). Trad. Jesus Ranieri. São Paulo: Boitempo, 2004.

MÉSZÁROS, I. Para Além do Capital: rumo a uma teoria da transição. Trad. Paulo Cezar Castanheira e Sérgio Lessa. São Paulo: Boitempo, 2011.

NOVAES, A. O novo espirito utópico. São Paulo: Sesc, 2016.

OLIVEIRA, J.; POMMIER, E. (Orgs.), Vocabulário Hans Jonas. Caxias do Sul: Educs, 2019.

TOLEDO, I. A. M., "O revisionismo histórico e a liquidação da tradição revolucionária". Projeto História, S. Paulo, v. 60, p. 351-357, out-dez. 2017. (Resenha).

TRAVERSO, E. Melancolia de Esquerda: marxismo, história e memória. Trad. André Bezamat. Belo Horizonte / Veneza: Âyiné, 2018.

VALVERDE, A. "Utopia”. In: OLIVEIRA, J. R.; POMMIER, E. (Orgs.). Vocabulário Hans Jonas. Caxias do Sul: EDUCS, 2019. p. 247-254.

VALVERDE, A. "Bloch e Jonas: ainda-não consciente, utopia concreta e ética de responsabilidade". In: CORREIA, A; DRUCKER, C; OLIVEIRA, J.; RIBEIRO, N. (Orgs.). Heidegger, Jonas, Levinas. São Paulo: ANPOF, 2017.

VALVERDE, A. "A docta spes de Ernst Bloch e o anti-utopismo de Hans Jonas", In: COSTA, A. F. V.; et al. (Org.). Heidegger, Jonas e Levinas. São Paulo: ANPOF, 2019. p. 43-58.

VIANA, F. A. M., A Utopia Concreta e o Ainda-não-Consciente na obra de Ernst Bloch. $306 \mathrm{f}$. Orientador: VALVERDE, A. Tese (Doutorado em Filosofia Política) - Pontifícia Universidade Católica de São Paulo, SP, 2015. 